Euskal ikerketen aldizkaria | Revue d'études basques |

Revista de estudios vascos | Basque studies review

$6 \mid 2001$

Numéro VI

\title{
Euskalduna eta Piarres Lafitte
}

\section{Amelia Hernandez}

URL : http://journals.openedition.org/lapurdum/1202

DOI : 10.4000/lapurdum.1202

ISSN : 1965-0655

Éditeur

IKER

\section{Édition imprimée}

Date de publication : 1 octobre 2001

Pagination : 195-203

ISBN : 2-84127-156-0

ISSN : $1273-3830$

Référence électronique

Amelia Hernandez, «Euskalduna eta Piarres Lafitte », Lapurdum [Linean], 6 | 2001, Sarean emana----an 01 juin 2009, kontsultatu 29 janvier 2020. URL : http://journals.openedition.org/lapurdum/1202 ; DOI : 10.4000/lapurdum. 1202 


\section{Amelia Hernandez}

\section{Euskalduna eta Piarres Lafitte}

\section{Eskualduna kazeta}

Martial-Henry Berdoly Mauleko suprefetak Le Réveil basque astekari errepublikarra kaleratu zuenean, 1886-ko abuztuan, Louis Etcheberry deputagai erregezaleak Eskualduna argitaratu zuen, 1887ko martxoaren 15ean, Le Réveil Basquek hautesle euskaldun guztiak erakarriko lituzkeen beldurrezl.

Izan ere, garai hartako politikariek ohitura zuten argitalpenenak kaleratzeko hauteskundeetan botuak lortzearren.

Hala ere, Le Réveil Basque desagertu egin zen hauteskundeak burutu zirenetik gutxira, 1894 ko uztailean, helburu politiko hutsarekin sortu baitzuten. Ostera, Eskualdunaren arduradunek astekaria argitaratzen jarraitu zuten, 1944ra arte, adieraziz, hauteskundeak jadanik amaiturik zeuden legez, politika pixka bat alde batera utziko zutela eta laborari eta familien gaiak landuko zituztela².

Horrela, Eskualdunan euskal herrietako gertakarien berri eman zuten "Nouvelles du Pays" atalean, nekazarien arazoez hitz egiten zuten "Laborarier" izenburupean eta erreklutatu eta gerlarien egoeraz "Nouvelles militaires" $\mathrm{n}^{3}$.

\footnotetext{
${ }^{1}$ Le Réveil Basqueren kontrako erasoak ugariak izan ziren Eskualdunan, batez ere hasierako zenbakietan : "Egia Errepublikaren eta Erligionearen gainean", "L'Autorité des chefs de famille", "La bonne foi du Réveil Basque". Eskualduna, 1887ko maiatzaren 15a; "Au Réveil Basque". Eskualduna, 1887ko irailaren 24a; "Au Réveil Basque". Eskualduna, 1887ko urriaren 21a; "La colère du Réveil Basque", Eskualduna, 1889ko apirilaren 19a, etab.

2 Eskualduna: "Gure irakurtzaleri", Eskualduna, 1890eko apirilaren 4a.

3 Eskuculdunan armadarenganako itxaropena agertu zuten : "Après Dieu, notre unique espérance pour le salut de la France est dans notre brave et admirable armée". "Soldadoguaco lege berria", Eskualduna, 1887ko irailaren 17a. Gai berberari buruz: "Nouvelles militaires. La Mobilisation", Eskualduna, 1887ko irailaren 17a: "Nouvelles militaires". Eskualduna, 1887ko urriaren 14a: "Recrutement", Eskualduna, 1887ko azaroaren 18a, etab.
} 
Dena dela, ez zuten politika erabat baztertu; eskuindarraren batasuna bilatu zuten ${ }^{4}$ eta Errepublikaren pentsamoldeari aurka egiten jarraitu zuten.

Kutsu erlijiosoa nabaria zen Eskualdunaren ia berri guztietan, Elizaren inguruan buruturiko ekintzak espreski aipatzeaz gain ${ }^{5}$. Izan ere, Eskualduna helburu politikoekin sortu zutenean, xede horiek bat zetozen Elizaren pentsamoldearekin. Are gehiago, Louis Etcheverry sortzailea, "politikaz, bihotzbihotzez bonaparte-tiarra" 6 zena, batzuetan kontra agertu zen Elizaren jokabidearen aurrean, errepublikazalea zelakoan?

Era berean, Eskualduna ez zen mazoizalea, ezta juduen zalea ere :

"Asmatzen dituzten tzarkeriak gure eta erligioneko guzien kontra egiteko framazondarrak juduen esku-makhil dire" 8.

Euskal herrietatik Ameriketarako emigrazioari buruz, Eskualdunan eten egitea proposatu zuten, herriak hustu ez zitezen ${ }^{9}$. Horrekin batera, hirietako protesta sozialak ez ziren Eskualdunaren gustukoak, komunistek sustatzen zituztelakoan:

"Polizak ez du buru egiten ahal gizon errabiatu horien. Gazeta gorriak berriz gizon horier etsenplu onak emaite orde gehiago asalda-arazten dituzte" 10 .

\footnotetext{
4 "ez zen xurien arteko batasunik : baziren erregetiarrak, bonapartixtak baieta errepublikano girixtinoak. Erregetiarrek ez zuten errege-gai bera sustengatzen, ez eta bonapartixtek inperadore-gai bera. Errepublikano girixtinoek kontra zituzten gorriak, hauiek erlisionerik ez baitzuten nahi : bai eta bertze xuriak, hauiek ez baitzuten uste izan zitakela errepublika onik". "Herric 25 urte". Herria. 1969.

5 "Nouvelles Religieuses", Eskualduna, 1887ko irailaren 17a: "Larressore", Eskualduna, 1887ko urriaren 28an: "Hazparneko predikuak", Eskualduna. 1888ko uztailaren 13a: "Installation du curé doyen", Eskualduna, 1889ko apirilaren 5ean: "Nominations dans le clergé", Eskualduna, 1893ko urtarrilaren 13a: "Une lettre de Léon XIII", Eskualduna, 1893ko urtarrilaren 27a; "Garizumako lehen igandearen Ebanjelioa", Eskualduna, 1894ko azaroaren 9a, etab.
}

${ }^{6}$ Lafitte, P. : Euskal Literaturaz, Erein, 1990, 225. or.

7 "Erromako politikaz duda azkar zonbait gora-behera", Lafitte. P.. Euskal literaturaz..., 225. or. Ideia berbera agertu du Michel Oronosek Louis Etcheverryz: "Etcheverry, aux sentiments bonapartistes bien marqués, s'attaque même à l'Eglise qu'il juge trop républicaine". Oronos. M. : L'information religieuse en basque dans les publications du Pays Basque Nord, de la fin du Concile Vatican II ( 8 décembre 1965) au Ve Synode romain (29 octobre 1977). Question pour une histoire future, Université de Bordeaux, 1982, 73. or.

8 "Juduak Frantzian nausi", Eskualduna, 1891 ko azaroaren 13a

9 "Nouvelles du Pays. Conthseilu bat", Eskualduna, 1887ko abenduaren 2a.

10 "La grève". Eskualduna, 1888ko abuztuaren 10a 
Laburbilduz, Javier Diaz Nocirekin batera esangu dugu Eskualdunak pentsamolde bat finkatu zuela irakurleen artean 1 , oso handia izanda astekari horren hedapena eta eragina herritarren artean, 8000 irakurle izatera helduz 1930. hamarkadaren hasieran.

Lafittek Eskualdunan 192 lean lehenengoz idatzi bazuen ere, Saint Pierre 1925ean astekariaren gidari izendatu zutenean ${ }^{12}$ hasi zen Lafitte maitasunez idazten : 81 artikulu argitaratu zituen Saint Pierren bost urtetako zuzendaritzapean. Lafitteren lankideak izen ziren Laurent Apestéguy, Jean Barbier, Louis Dassance, Dominique Dufau, Pierre Duhour, Jean Elissalde "Zerbitzari", Jean Etchepare, Goyheneche, Julien Héguy, Michel Iriart, Gratien Istilart, Piarres Lafitte, Leon Léon, Jules Moulier “Oxobi” eta Maurice Otacéhé13.

Hala ere, 1929ko abuztutik 1933ko abendura arteko Eskualdunak jaso zituen Lafitteren lan gehienak, zeren eta Michel Iriartek, Ustaritzeko erretora, "Ebanjelio" izenburuko artikulua prestatzen baitzuen Eskualduna astekarirako eta 1929an hil zenean Lafittek ekin zion!4 lan horri.

1930ean Jean Saint Pierre Carthageko artzapezpikuaren laguntzaile izendatu zuten eta Dominique Soubelet Eskualdunaren zuzendaritzarako aukeratu, kalonje bilakatzearekin batera. Aurreko parragrafoan aipatu ditugun idazleei Xalbat Arotçarena gehitu zitzaien lankide bezala ${ }^{15}$. Soubeletek astero idatzi zuen Eskualdunaren lehenengo orrialdean : apezpikuaren hitzak goratu egin zituen, Espainiako Errepublika arbuiatu, soldado frantziarrak adoretu, etab. Piarres Lafittek ia zenbaki guztietan idatzi zuen Ebanjelioz -

11 Díaz Noci, Javier : Euskal prentsaren sorrera eta garapena (1834-1939). Donostia, Eusko Ikaskuntza, 1995, 51. or.

12 Eskualdunaren zuzendari izendatu zutenean Jean Saint Pierre astekariaren lehenengo orrialdean idazten hasi zen, J.S.P.-z sinatuz. Polika eta ekonomia gaiak oinarritzat harturik komentarioak egiteaz gain, herrietako gertakizunak eman zituen aditzera bigarren edo hirugarren orrialdeetan.

13 Aipatu idazleak Eskualdunaren azterketa lanean aurkitu ditugunak dira. Hala ere, "Herria 25 urte" artikuluan Donech, Larrieu eta Valence lankideak ere aipatzen dira Saint-Pierren garaikide bezala, guk geuk orduko Eskualdunaren orrialdeetan aurkitu ez ditugunak.

14 Xarriton, P.: Jean Etchepare mirikuaren (1877-1935) idazlanak. I Euskal Gaiak, 1984, Donostia, Elkar. 351. or.

15 "Herria 25 urte" artikuluan lankide gehiago aipatzen dute Soubeleten garaian idatzi zutenen artean : Athor, Dirassar, Esperne, Etcheverry Milafrankako erretorea, J. B. Etcheverry, Iturbide, Lompageu eta Olhagaray. 
142 artikuluetatik, 128 ziren "Ebanjelioa" izenburudunak- eta liburu berriez: noizbehinka, P.L.-z sinaturik.

Soubeleten garaiko Eskualdunak Frantzia eta Italiaren arteko hitzarmenaren alde agertu zen ${ }^{16}$, Hitlerek poterea eskuratu zuelakoaren beldur baitzen ${ }^{17}$. Tokiko politikaren alorrean, Eskualdunan Ybarnégaray aurkeztu zuten euskal politiko eta hizlari hobezin bezala, idealizaziora eramateraino :

"C'est devant une assistance fatiguée par de trop longs discours que notre député basque Jean Ybarnégaray a fait entendre sa remarquable interpretation. Fermeté du ton, logique du raisonnement, ironie mesurée, éloquence du débit, tout dans cette intervention révéle le grand orateur" 18

1937an Soubeletek zuzendaritza utzi zuen, gaixorik baitzegoen, eta Xalbat Arotçarenak hartu, martxoaren 24an ${ }^{19}$.

Arotçarenarekin, eta Bigarren Mundu-Gerraren urteak zirelarik, astekariak bat egin zuen Frantzian ezarritako Vichyko gobernu zein Pétainen pentsabidearekin : Révolution Nationalaren alde agertu zen20 - "lana, familia eta aberria" leloari jarraituz-, frantses guztiak Frantziaren batasunaren alde adoretu zituen ${ }^{21}$ eta Vichyko Milice Française aintzat hartu zuen ${ }^{22}$.

Berriro ere Eskualdunak komunismoarekiko beldurra agertu zuen :

"Egungo-egunean, gehiago ezin ukhatuzko gauza ez othe da: komunista guri bihotzeko phisu-minenen trenkatzerat doala... Komunistak

16 "L'amitié Franco-Italienne", Eskuclduna 1932ko martxoaren $18 \mathrm{a}$.

17 "Sekulan ez du Frantziak orai baino armada azkar baten beharra izan. Alemaniak Hiłler nausi jarriz geroztik, ez du bertzerik asmatzen baizik eta gerlaren berriz phiztea". "Berriak. Frantzia. Egon gaiten azkar" Eskualduna, 1933ko irailaren Ia.

18 "Vibrante interpellation đu député basque Ybarnégaray". Eskualduna. 1934ko urtarrilaren 19a. Era berean: "Il est de droite parce qu'il représente à la Chambre une foi et des traditions comme il n'en fleurit qu'au Pays basque, à l'ombre dorée de ses sanctuaires, sous le signe d'une piété sans apprêt, sans trouble, simple et nue comme la pierre dépouillée de ses cimes", Eskualduna, 1932ko irailaren 30a.

19 "euskalzale argitsu eta sutsua izan arren. Ac゙ion françcisen pentsakeratik hurbil zegoena", Oronos, M. aipatu liburua, 73. or.

20 S. A. : "Bihotzez Marechalarekin", Eskualduna 1942ko maiatzaren Ia.

21 S. A. : "Hitz bakhar... bi sentsu". Eskualduna, 1942ko urtarrilaren 23a; S. A. : "Révolution Nationale", Eskualduna, 1942ko maiatzaren 19a; S. A. : "Révolution Nationale", Eskualduna 1942ko abuztuaren $7 \mathrm{a}$.

22 S. A. : "Bihotzetik gure agurra igortzen diogu Baionan jarri berri zaukun "La Milice Française" horri, esperantcha baitugu... gizontasuna... garbitasuna derauzkula gure choko huntarat ekharten", Eskualduna. 1944ko ekainaren 23a. 
mehatchatzen dituela oro, bai Herria, bai familia, bai erlisionea, bai bakea?"'23

Arotçarenaren garai hartan Eskualduna Francoren alde ere agertu zen24. Horrela, Frankistek Bilbao hartu zutenean, honako lerro hauek argitaratu zituzten astekarian :

"Bilbaoko jendea alegera zen Francoren soldadoak ikustearekin... Zer atsekabe guretzat eskualdunak ikustea, komunichtekin eskuz ikustea, tresna berak eskuetan, Francoren soldadoen kontra... Bazutena arrazoinik aski komunizteri laguntza emaiteko? Hori bertzerik da. Guri hasteko ez iduri... Eskualdun guziak eman balire Francoren alde, Gipuzkoakoak eta Bizkaiakoak. Alabakoak bezala guri iduri odol gutiago izanen zela Espainian"25

eta itxaropentsu agertu zen Alemania Bigarren Mundu-Gerraren garaile suertatzeko aukeraren aurrean :

"Beraz salbamenduraz heltzeko bide bakhar bat dugu... Bide eta athe bakhar bat, ez biga: Alemaniaren bitoria... Zombat erresuma komunismoaren pozoin latzgarriak pozoindaturik dauzkanak" 26

Alemanenganako begikotasuna zela eta, Eskualdunaren irakurle asko kazetaren etsai bilakatu ziren eta salmenten kopuruak beherantz egin zuen, 2.200 aletara helduz 27 .

Era berean, Arotçarena Eskualdunaren zuzendari izendatzearekin, Lafittek asko gutxitu zuen astekarirako lana : hamabost artikulu baino ez ${ }^{28}$.

23 S. A. : Eskualduna, $1937 \mathrm{ko}$ apirilaren 9a.

24 "Eskualduneri Francoren hitzak", Eskualduna 1937ko azaroaren 28a.

25 "Auzo erresumetan", Eskualduna 1937ko uztailaren 2a.

26 S. A. : "Utz haurkeriak", Eskualduna, 1942ko urriaren 16 a.

27 "Herria 25 urte... aipatu artikulua.

28 Ikus Eranskina. 


\section{Piarres Lafitteren estatus intelektuala Eskualdunaren gainontzeko lankideekiko.}

Eskualdunako Piarres Lafitteren eta garaiko lankideen emaitzak biltzearren, hona hemen 1920 . eta 30. hamarkadetako idazleen zerrenda eta astekarian argitaraturiko artikuluen kopuruak:

\begin{tabular}{|c|c|c|c|}
\hline Lankideak & $\begin{array}{l}\text { Eskualduna } \\
(1921-1940)^{29}\end{array}$ & & $\begin{array}{l}\text { Adina } \\
\text { 1940an }\end{array}$ \\
\hline Dufau, Dominique & 3 & & \\
\hline Héguy, Julien & 3 & $\dagger 1930$ & 70 \\
\hline Larzabal, Pierre & 5 & & 25 \\
\hline Camino, A. & 6 & & \\
\hline Echegoyen, D. & 8 & & \\
\hline Arbeletche, $\mathrm{H}$. & 9 & & \\
\hline Lassalle, Leon & 9 & & 59 \\
\hline Ybarnégaray, Jean & 11 & & 57 \\
\hline Minvielle & 13 & & \\
\hline Leon, Léon & 15 & & 44 \\
\hline Iriart, Michel & 19 & & \\
\hline Dassance, Louis & 22 & & 52 \\
\hline Istillart, Gratien & 35 & & 76 \\
\hline Souberbielle, Maurice & 56 & & 67 \\
\hline Goyeneche & 69 & & \\
\hline Barbier, Jean & 79 & $\dagger 1931$ & 56 \\
\hline Moulier, Jules & 82 & & 52 \\
\hline Apestéguy, Laurent & 109 & $\dagger 1928$ & 41 \\
\hline Etchepare, Jean & 121 & $\uparrow 1935$ & 58 \\
\hline Menditte, A. de & 129 & & \\
\hline Elissalde, Jean & 159 & & 57 \\
\hline Saint-Pierre, Jean & 180 & & 56 \\
\hline Lafitte, Piarres & 238 & 3 & \\
\hline Arotçarena, Salbat & 248 & & \\
\hline Irigarai, Pablo Fermín & 366 & & 71 \\
\hline Soubelet, Dominique & 370 & & 43 \\
\hline Otacéhé, Maurice & 428 & & \\
\hline Duhour, Pierre & 458 & & 50 \\
\hline
\end{tabular}

Laukiak erakusten digun legez, Eskualdunan idatzi zuten 28 idazleengandik 18ren jaiotze data ezagutzen dugu. Hogeitabost urteko Pierre Larzabal izan ezik, guztiak ziren Lafitte baino zaharragoak. Hala ere, artiku-

29 Ez dugu Eskualdunaren 1920ko alerik topatu, ez Belokeko, ez Baionako ezta Euskal Museoko liburutegietan ere. 
luen kopuruari begiratuz gero, ikusiko dugu 1940an bost idazlek baino ez zutela Lafitte gainditzen Eskualdunan argitaratzeari zegokionez.

Argi dago, beraz, Lafitte ia gazteena bazen ere, intelektual emankorrenetariko bat izan zela 1920. eta 30. hamarkadetako Eskualdunan.

\section{ERANSKINA}

\section{Piarres Lafittek Eskualdunan idatzitako artikuluak :}

"Behenabarren", 1921-9-30

"Koplak. Larressore", 1921-10-28

"Hilen otoitza", 1921-12-21

"Marroken", 1925-7-24

"Exxekanderia", 1925-7-24

"Lurdeko berria", 1925-7-31

"Mise au point.", 1925-8-7

"Erramun gorria", 1925-8-14

"Laiko bati", 1925-8-21

"Etchekandrea", 1925-8-28

"Dendarien artean", 1925-9-25

"Otsoa", 1925-10-9

"Hergaray", 1925-11-6

"Laborarier", 1926-9-3

"Une grande découverte", 1926-9-24

"Gure sodadoen berri", 1926-11-5

"Liburu berri", 1932-4-15

"Une grande découverte française", 1927-8-12

"Lan eder bat", 1928-3-9

"Jarraik Etsaiari", 1928-7-6

"Bakantzak", 1928-7-20

"Hiriatekoan", 1928-7-27

"Lau leize", 1928-7-27

"Batasun", 1928-8-24

"Donadoen lana", 1928-8-31

"Zoziaoizt-azia", 1928-9-14

"Albert Bidegain", 1928-9-28

"Begiak idek", 1928-10-5

"Une grande découverte", 1928-10-19

"Eskuz esku", 1928-12-28

"Iriart kalonjea", 1928-4-26

"Ustaritz. Saski naski", 1928-8-9

"Euskera zertan den", 1930-12-19

"Mgr. Diharassarry", 1931-4-24

"Ebanjelio", 1929-8-2; 1929-8-9; 1929-8-16; $1929-8-23 ; 1929-8-30 ; 1929-9-6 ; 1929-9-13$; 1929-9-20; 1929-9-27; 1929-10-11; 1929-10-18; 1929-11-1; 1929-11-9; 1929-11-15; 1929-11-22; 1929-1129; 1929-12-6; 1929-12-13; 1929-12-20; 1929-12-27; 1930-1-3; 1930-1-10; 1930-1-17;
1930-1-24; 1930-1-31; $1930-2-14 ; 1930-2-21$; $1930-3-7 ; 1930-3-14 ; 1930-3-28 ; 1930-4-4 ; 1930-$ $4-11 ; 1930-4-18 ; 1930-4-25 ; 1930-5-2 ; 1930-5-9$; $1930-5-16 ; 1930-5-23 ; 1930-5-30 ; 1930-6-6$; 1930-6-13; 1930-6-20; 1930-6-27; 1930-7-4; $1930-7-11 ; 1930-7-18 ; 1930-7-25 ; 1930-8-1$; $1930-8-8 ; 1930-8-15 ; 1930-8-22 ; 1930-8-29$; $1930-9-8 ; 1930-9-12 ; 1930-9-26 ; 1930-10-3$ $1930-10-10 ; 1930-10-17 ; 1930-10-24 ; 1930-10-$ $31 ; 1930-11-7 ; 1930-11-14 ; 1930-11-21 ; 1930-11-$ 23 ; 1930-12-5; 1930-12-12; 1930-12-19; 1930-12$26 ; 1931-1-2 ; 1930-1-9 ; 1931-1-16 ; 1931-1-23$; 1931-1-30; 1931-2-6; 1931-2-13; 1931-2-20; 1931-2-27; 1931-3-6; 1931-3-13; 1931-3-20; 1931-3-27; 1931-4-3; 1931-4-10; 1931-4-17; $1931-4-24 ; 1931-5-1 ; 1931-5-8 ; 1931-5-15 ; 1931$. $5-19 ; 1931-5-22 ; 1931-6-3 ; 193\}-6-26 ; 1931-7-3$; 1931-7-10; 1931-7-24; 1931-7-31; 1931-8-7 1931-8-14; 1931-8-21; 1931-8-28; 1931-9-4; $1931-9-11 ; 1931-9-18 ; 1931-10-9 ; 193\}-10-23$; 1931-10-30; 1931-11-6; 1931-11-20; 1931-12-4; 1931-12-11; 1931-12-18; 1932-1-1; 1932-1-8; $1932-1-15 ; 1332-1-22 ; 1932-1-29 ; 1932-2-5$; $1932-2-19 ; \quad 1932-2-26 ; 1932-3-25 ; 1932-4-1$; $1932-4-8 ; 1932-4-22 ; 1932-4-29 ; 1932-5-6 ; 1932-$ $5-20 ; 1932-5-27 ; 1932-6-2 ; 1932-6-10 ; 1932=6-$ $17 ; 1932-6-24 ; 1932-7-1 ; 1932-7-8 ; 1932-7-15$; 1932-7-22; 1932-7-29; 1932-8-5; 1932-8-12; $1932-8-13 ; 1932-8-26 ; 1932-9-2 ; 1932-9-9 ; 1932-$ $9-16 ; 1932-9-23 ; 1932-9-30 ; 1932-10-7 ; 1932-10-$ $14 ; 1932-10-21 ; 1932-10-28 ; 1932-11-4 ; 1932-11-$ $11 ; 1932-11-18 ; 1932-11-23 ; 1932-12-2 ; 1932-12-$ 9; 1932-12-16; 1932-12-23; 1932-12-30; 1933-113; 1933-1-20; 1933-1-27; 1933-2-3; 1933-2-10; 1933-2-17; 1933-3-17; 1933-3-31; 1933-4-14; 1933-4-21; 1933-5-5; 1933-5-19; 1933-5-26 $1933-6-9 ; 1933-6-23 ; 1933-7-7 ; 1933-7-14 ; 1933-$ $7-28 ; 1933-8-11 ; 1933-8-25 ; 1933-9-8 ; 1933-9-$ $22 ; 1933-10-6 ; 1933-10-27 ; 1933-12-15 ; 1935-2-$ $22 ; 1935-3-22 ; 1935-7-5$ 
"Eskualdun menderen mende", 1933-4-14; 1933-7-7; 1933-10-6; 1933-11-3; 1933-12-8; 1933-12-15; 1933-12-22; 1933-12-29

"Les Basques à Paris", 1933-4-28

"Basques à Paris", 1933-10-20

"Araudia", 1933-12-8; 1933-12-15; 1933-12-29

"Kurutzea", 1935-12-27

"Ustaritz. Euskal etxea", 1936-1-3

"Basa-erlisione bat", 1936-3-13

"Cagularrak", 1938-3-18

"Berritz hemen", 1938-10-14

"Pariseko biltzarra", 1939-3-3

"Azlarate", 1941-1-3

"Eskual Herriaren alde", 1941-5-23
"Hiruak bat", 1941-6-27

"B delakoak", 1941-7-4

"Herria ezagutu", 1941-7-18

"Kasu haurreri", 1941-8-1

"Mlle. Kinkanputz", 1941-8-15

"L'enseignement régional à l'ecole", 1941-10-10

"Vichyrako beilariak", 1941-11-24

"Eskuarazko katichima", 1941-12-19

"Lege berri baten ondorio", 1942-1-16

"Eskuarazko erakaspena", 1942-1-23

"Familien chokoa", 1943-5-14

"Larrouy Jacques Bithirineko jaun erretoria", 1944-7-21

\section{BIBLIOGRAFIA}

EUSKALTZAINDIA : Piarres Lafitte-ri omenaldia, Bilbo, Iker, 1983.

HARITSCHELHAR, Jean eta beste batzuk : "Hommage à Pierre Lafitte". Bulletin du Musée Basque, 1986, 113-114 zkiak.

"Herria 25 urte", Herria, 1969.

LAFITTE, P. : Euskal literaturaz, San Sebastian, Erein. 1990. 